Article

\title{
Understanding Parent Support for Physical Activity among Parents of Children and Youth with Disabilities: A Behaviour Change Theory Perspective
}

Rebecca Bassett-Gunter ${ }^{1 *}$, Sunita Tanna ${ }^{1}$, Kelly Arbour-Nicitopoulos ${ }^{2}$, Ryan E. Rhodes ${ }^{3}$ and Jennifer Leo ${ }^{4}$

Received: 6 June 2019; Accepted: $5^{\text {th }}$ May 2020; Published: $1^{\text {th }}$ August 2020

\begin{abstract}
Parent support facilitates physical activity among children and youth with disabilities (CYD). Parent physical activity support is a behaviour unto itself which requires motivation and effort, yet its predictors are not well understood. Guided by the theory of planned behaviour (TPB) and multi-process action control (M-PAC) framework, the study aimed to identify predictors of physical activity support among parents of CYD $(\mathrm{N}=95 ; 83.2 \%$ female). TPB and M-PAC variables were assessed, followed by parent physical activity support behaviour four weeks later. Regression analysis identified TPB (i.e., perceived behavioural control for child physical activity, intention) and M-PAC (i.e., behavioural regulation, habit, and identity) predictors of parent physical activity support. The inclusion of M-PAC variables into the model explained an additional $18 \%$ variance in parent physical activity support. There is value in understanding both pre- and post-intentional predictors of parent physical activity support. This study can inform future research and interventions to support parent physical activity support to facilitate physical activity among CYD.
\end{abstract}

Keywords: Theory of planned behaviour; multi-process action control framework; pre-intentional; post-intentional

\section{Introduction}

There are myriad benefits of physical activity (PA) for children and youth with disabilities (CYD; Bloemen, Van Wely, Mollema, Dallmeijer, \& de Groot, 2017), yet poor PA participation rates are observed (Perry \& Weiss, 2014). Parents play an important role in supporting PA for their CYD (An \& Goodwin, 2007) and although many have good intentions to do so (Tanna, Arbour-Nicitopoulos, Rhodes, \& Bassett-Gunter, 2017), often times these intentions do not translate into behaviour (e.g., Jeong, Kim, \& Lee, 2015). Given the important role of parental support, there is a need for research to understand factors that can facilitate parent PA support among CYD such that effective interventions can be informed.

A recent systematic review suggested that interventions to increase PA among CYD should include parents (Bloemen et al., 2017). Indeed, parent support for PA (i.e., parent PA support) has been established as an important correlate of children's PA (Beets, Cardinal, \& Alderman, 2010). Parents can provide critical active (e.g., financial support, transportation) and persuasive support (e.g., encouragement, information; Beets et al., 2010). Meta-analytic 
evidence indicates there is a medium-sized effect between parent PA support and child PA (Yao \& Rhodes, 2015).

It has been suggested that parent PA support is particularly important for CYD and a key correlate of PA participation (Antle, Mills, Steele, Kalnins, \& Rossen, 2007). CYD with high levels of parent PA support had a two-fold increase in PA participation compared to CYD with low levels of parent PA support (Kowalchuk \& Crompton, 2009). Although many parents of CYD have good intentions to support their child's PA (Jeong et al., 2015), they often face challenges in doing so (Bassett-Gunter, Ruscitti, Latimer-Cheung, \& FraserThomas, 2017; Jeong et al., 2015). In addition to challenges faced by parents of typically developing children (e.g., environmental, occupational and policy barriers; Rhodes et al., 2016), parents of CYD face heightened challenges such as concerns about their child's safety, limited knowledge and skill among instructors, limited availability of high quality and accessible programs (Bassett-Gunter et al., 2017; Jeong et al., 2015), lack of support for parents, and parents' difficulty developing behaviour control and behaviour regulatory strategies (Tanna et al., 2017). These challenges include both pre-intentional factors (i.e., affect parents' motivation to provide parent PA support) and post-intentional factors (i.e., affect parents' ability to translate motivation into behaviour). There is a need for research to understand both pre- and post-intentional factors related to parent PA support for CYD such that interventions and strategies to enhance parent PA support can be informed, and PA participation among CYD can be enhanced.

Interventions in the PA domain (i.e., including interventions targeting parent PA support) are more likely to be effective if they are developed based on a theory of behaviour change (Rhodes, Taylor \& McKay,2010). The theory of planned behaviour (TPB) is a behaviour change theory that has been applied in research examining parent PA support among children and youth without disabilities (Rhodes, Berry, Craig, Faulkner, LatimerCheung, Spence \& Tremblay, 2013) and CYD (Jeong et al., 2015). The TPB suggests that an individual's intention (i.e., motivation) to perform a given behaviour (e.g., parent PA support) is influenced by pre-intentional constructs including behavioural (i.e., attitudes), normative (i.e., subjective norms), and control (i.e., perceived behavioural control; PBC) beliefs about the behaviour (Ajzen, 1991). In turn, intentions and PBC together are theorized to predict behaviour.

When the TPB was applied in research among parents of children without disabilities, attitudes and PBC predicted parents' intentions to provide PA support, whereas PBC emerged as the only significant predictor of parent PA support behaviour (Rhodes et al., 2013). When the TPB was applied in research examining parent PA support for CYD, behavioural and normative beliefs explained $46 \%$ of the total variance in parents' intention to provide PA support, and intention was the only significant predictor of parent PA support behaviour (Jeong et al., 2015). Jeong and colleagues' (2015) study provides great value in a first effort to examine parent PA support for CYD within the context of a behaviour change framework. There has been a call to further examine PA support among parents of CYD within the context of the TPB (Jeong et al., 2015). However, in order to expand our understanding and inform the development of optimally effective interventions to enhance parent PA support for CYD, we must look beyond intentions and focus on post-intentional factors that predict behaviour. While the TPB clearly has utility, it has been criticized for its inability to explain why strong intentions do not always translate into behaviour (Conner \& Norman, 2005). The "intention-behaviour gap" has been observed across many studies (Rhodes \& de Bruijn, 2013) and has been observed among parents of children without disabilities (Rhodes et al., 2016) and CYD (Jeong et al., 2015). While most parents of children with and without disabilities are well intentioned with regards to providing parent 
PA support (Jeong et al., 2015; Rhodes et al., 2013), it seems there are additional factors at play in translating intentions into behaviour. Therefore, it is necessary to consider postintentional factors that may predict parent PA support and inform effective interventions.

Efforts to understand the intention-behaviour gap have been made through examining behaviour within action control models, which focus on post-intentional constructs that help translate intentions into behaviour (Rhodes, 2017). The multi-process action control (MPAC) framework (Rhodes, 2017) is one such model that has been applied within parent PA support research (Rhodes et al., 2016). M-PAC builds upon tenets of the TPB in which reflective processes (i.e., pre-intentional constructs) such as instrumental attitude (e.g., expected benefit of performing the behaviour), affective judgments (e.g., expected emotions that will occur during the behaviour), perceived capability (e.g., perceptions of physical and mental capability to perform the behaviour) and perceived opportunity (e.g., whether they have time and access to carry out the behaviour) determine motivation to form intentions. In addition, M-PAC adds the notion that as individuals begin to successfully translate intentions into behaviour, they are further guided by regulation and reflexive processes (i.e., post-intentional constructs). The regulation process involves behavioural regulation strategies such as action and coping planning, and self-monitoring (Rhodes, 2017). These behavioural regulation strategies are critical until the individual develops more reflexive processes to further assist in maintaining behaviour such as through habit and identity (Rhodes, 2017). Habit is a process by which a stimulus cues a response (Lally \& Gardner, 2013), therefore requiring low intentions and increases the efficiency of translating intentions into behaviour (Rhodes \& de Bruijn, 2013). Another reflexive construct is identity, which involves how one views themselves in a given role (Burke, 2006). Similar to habit, identity is formed through behaviour maintenance and therefore reduces the effort required in translating intentions into behaviour as individuals identify themselves with the behaviour (e.g., a routine exerciser; Rhodes et al., 2016). In applying the M-PAC framework to understanding parent PA support, behavioural regulation strategies, habit, and identify must be considered (Rhodes, 2017).

There is little research to inform our understanding of the pre- or post-intentional theoretical factors that predict parent PA support among parents of CYD. Jeong and colleagues (2015) have considered pre-intentional factors related to parent PA support within the context of the TPB. There are few studies that consider post-intentional factors related to parent PA support among parents of CYD (Tanna et al., 2017). This study examined a telephone-assisted planning intervention for promoting parent PA support among CYD and found that habit, identity, and behavioural regulation were correlated with parents' PA support behaviour (Tanna et al., 2017). These results suggest that indeed it is important to further understand the role of post-intentional factors in facilitating parent PA support (Tanna et al., 2017). There is a need for further research to examine pre- and postintentional factors related to parent PA support among parents of CYD.

Therefore, the primary purpose of the current study was to examine pre- (i.e., TPB) and post- (i.e., M-PAC) intentional predictors of PA support among parents of CYD. The study was designed to build upon and address limitations of previous research regarding parent PA support (Francis et al., 2004; Rhodes et al., 2013) through (1) considering both pre and post-intentional factors related to parent PA support, (2) improved measurement of theoretical constructs, and (3) the use of a prospective study design. Based on previous research, it was hypothesized that intention (Jeong et al., 2015) and PBC (Rhodes et al., 2013), as well as behavioural regulation, habit and identity (Tanna et al., 2017) would positively predict PA support among parents of CYD. 


\section{Materials and Methods}

\section{Participants}

Participants were recruited through North American disability organizations that serve families of CYD (e.g. Easter Seals, Special Olympics, Parents Helping Parents). Participants were eligible if they: (a) were a parent, (b) had at least one child between 5-30 years of age who had a disability that was physical, sensory, psychological or developmental in nature, (c) lived in North America, and (d) were proficient in English. A total of 114 parents of CYD were recruited. The inclusion age of CYD was derived with guidance from the United Nations, which includes individuals with disabilities up to 24 years in their definition of children and youth (United Nations, 2012). Some parents with children between the ages of 24-30 wished to participate and argued that their older child required the same parent PA support as younger children. Accordingly, the researchers extended the inclusion age to 30 years, as young adults with severe disabilities do indeed require continued parent support (Stewart, Law, Rosenbaum \& Willms, 2002). The extended age range also allowed for an increased sample size. The data set was collected between January 2015 and May 2016. The research protocol was approved by the Office of Research Ethics Human Research Committee at York University. Informed consent was obtained from each participant.

\section{Measures}

\section{Theory of planned behaviour constructs}

It is recommended that TPB measures are developed through an elicitation approach to identify salient behavioural (i.e., attitudes), normative (i.e., subjective norms), and control (i.e., PBC) beliefs that are population-specific (Hancock, 2013; Rhodes, 2004). An elicitation approach was employed to inform the development of a tool to measure attitudes, subjective norms, and PBC. Parents' behavioural beliefs regarding parent PA support and child PA participation have been found to predict parents' intentions to provide parent PA support (Rhodes et al., 2013). Jeong and colleagues (2015) assessed parents' salient beliefs in relation to parent PA support behaviour only. Therefore, to extend this research, salient beliefs regarding both parent PA support and child PA participation were measured for the current study.

Prior to data collection for the main study, a small sample $(n=28)$ of parents of CYD completed an online, open-ended questionnaire to elicit behavioural, normative, and control beliefs regarding two targets (1) child PA (i.e., PA participation among their CYD), and (2) parent PA support (i.e., supporting their CYD to participate in PA). The questionnaire was developed based on recommendations for constructing a TPB elicitation questionnaire (Ajzen, 2002). Table 1 includes examples of questions used to elicit beliefs regarding each construct.

Responses were analyzed using an established content analysis process (Hancock, 2013). Using a line-by-line coding procedure, a thematic coding framework was developed and a list of beliefs was generated and then categorized under the relevant TPB constructs. Responses were ranked to identify the top $75 \%$ responses (Francis et al., 2004) and the top five to eight salient beliefs for each construct were then identified as these are expected to predict the majority of the variance in any behaviour (Rhodes et al., 2004). An additional three and four items were included for both behavioural and control beliefs, respectively, as the researchers felt these items were necessary to cover the breadth of these constructs (Francis et al., 2004). The items added for behavioural beliefs were (1) put my child at risk for injuries and pain; (2) take time away from my other commitments such as family and work; and (3) be frustrating for me. The items added for control beliefs were (1) your child 
had limited time due to school and other commitments; (2) the activities were not necessarily safe for your child; (3) you are concerned about your child's safety; and (4) you are feeling tired, frustrated, or in a bad mood.

Table 1. Example of Theory of Planned Behaviour elicitation questionnaire items

\begin{tabular}{|c|c|}
\hline Constructs & Example question \\
\hline Attitude (child PA): & $\begin{array}{l}\text { What do you believe are the benefits of your child participating in } \\
60 \text { minutes of physical activity each day? }\end{array}$ \\
\hline $\begin{array}{l}\text { Attitude (parent PA } \\
\text { support): }\end{array}$ & $\begin{array}{l}\text { What do you believe are the benefits of you supporting your child to } \\
\text { participate in } 60 \text { minutes of physical activity each day? }\end{array}$ \\
\hline $\begin{array}{l}\text { Subjective norm (child } \\
\text { PA): }\end{array}$ & $\begin{array}{l}\text { Are there any individuals or groups who would approve of your } \\
\text { child participating in } 60 \text { minutes of physical activity each day? }\end{array}$ \\
\hline $\begin{array}{l}\text { Subjective norm (parent } \\
\text { PA support): }\end{array}$ & $\begin{array}{l}\text { Are there any individuals or groups who would approve of you } \\
\text { supporting your child to participate in } 60 \text { minutes of physical } \\
\text { activity each day? }\end{array}$ \\
\hline $\begin{array}{l}\text { Perceived behavioural } \\
\text { control (PBC; child PA): }\end{array}$ & $\begin{array}{l}\text { What factors or circumstances would make it difficult or impossible } \\
\text { for your child to participate in } 60 \text { minutes of physical activity each } \\
\text { day even if she/he really wanted to be active on a regular basis? }\end{array}$ \\
\hline $\begin{array}{l}\text { Perceived behavioural } \\
\text { control (PBC; parent PA } \\
\text { support): }\end{array}$ & $\begin{array}{l}\text { If you really wanted to support your child to participate in } 60 \\
\text { minutes of physical activity each day, what factors or circumstances } \\
\text { would make it difficult or impossible to do so? }\end{array}$ \\
\hline
\end{tabular}

The final items used in the questionnaire for the full sample are presented in Table 2. Each item was assessed on a 5 -point Likert-type scale $(1=$ strongly disagree to $5=$ strongly agree). Prior to completing the questionnaire, participants were given the following definitions of (1) child PA: "physical activity includes active play (e.g., riding a bicycle, playing at the park), sports (e.g., soccer, basketball) and other organized physical activities (e.g., swimming, dance lessons)" and (2) parent PA support: "parents can provide support to their children to help them achieve 60 minutes of physical activity each day. Providing support for your child to be physically active can be done through many different activities such as providing transportation to sport activities, playing sports with them, or encouraging them to play outside." Below are example items from each subscale:

\section{Theory of planned behaviour measures}

Attitude (child PA): Participants rated their agreement with nine items anchored by "if my child were to engage in 60 minutes of physical activity daily, it would" followed by statements such as: 1) benefit my child's physical health; and 2) help my child be social (Cronbach's $\alpha=0.88 ; \mathrm{KMO}=0.86 ; \chi_{2}(36)=662.89, \mathrm{P}<.001$ ).

Attitude (parent PA support): Participants rated their agreement with ten items anchored by "supporting my child to engage in 60 minutes of physical activity each day, would" followed by statements such as: 1) help me bond with my child; and 2) cause me to worry about my child (e.g., safety, well-being) (Cronbach's $\alpha=0.85 ; \mathrm{KMO}=0.74 ; \chi^{2}(45)=$ 433.21, $\mathrm{P}<.001$ ).

Subjective norm (child PA): Participants rated their agreement with five items anchored by "the following people think my child should engage in 60 minutes of physical activity each day" followed by individuals such as: 1) medical professionals (e.g., doctors, therapists); and 2) school (e.g., teachers; Cronbach's $\alpha=0.82 ; \mathrm{KMO}=0.81 ; \chi^{2}(10)=185.75$, $\mathrm{P}<.001)$. 
Table 2. Theory of planned behaviour (i.e., pre-intention) beliefs elicited after content analysis

\begin{tabular}{|c|c|c|}
\hline Construct & Child PA & Parent PA support \\
\hline Attitude & $\begin{array}{l}\text { 1. Benefit my child's physical health } \\
\text { 2. Help my child be social } \\
\text { 3. Be fun for my child } \\
\text { 4. Benefit my child's mental health } \\
\text { 5. Be unenjoyable for my child } \\
\text { 6. Contribute positively to my child's } \\
\text { mental health } \\
\text { 7. Help my child feel a sense of normalcy } \\
\text { 8. Help my child develop various skills } \\
\text { 9. Put my child at risk for injuries and pain }\end{array}$ & $\begin{array}{l}\text { 1. Instrumental*: } \\
\text { 2. Help me bond with my child } \\
\text { 3. Allow me to watch my child improve and } \\
\text { achieve success } \\
\text { 4. Allow me to watch my child experience } \\
\text { happiness, fun and feelings of normalcy } \\
\text { 5. Allow me to be physically active while } \\
\text { participating with my child } \\
\text { 6. Allow me to act as a role model and } \\
\text { mentor for my child } \\
\text { 7. Affective*: } \\
\text { 8. Cause me to worry about my child (e.g. } \\
\text { safety, well-being) } \\
\text { Be unenjoyable for me } \\
\text { 10. Depend on my child's mood and } \\
\text { emotions } \\
\text { 11. Take time away from my other } \\
\text { commitments such as family and work } \\
\text { 12. Be frustrating for me }\end{array}$ \\
\hline $\begin{array}{r}\text { Subj } \\
\text { no }\end{array}$ & $\begin{array}{l}\text { 1. Medical professionals (e.g., doctors, } \\
\text { therapists) } \\
\text { 2. School (e.g., teachers) } \\
\text { 3. Recreation/Sports team leaders (e.g., } \\
\text { staff, coaches) } \\
\text { 4. Disability organizations/programs } \\
\text { 5. Family (e.g., immediate, extended, } \\
\text { spouse) }\end{array}$ & $\begin{array}{l}\text { 1. Medical professionals (e.g., doctors, } \\
\text { therapists) } \\
\text { 2. School (e.g., teachers) } \\
\text { 3. Recreation/Sports team leaders (e.g., } \\
\text { staff, coaches) } \\
\text { 4. Disability organizations/programs } \\
\text { 5. Family (e.g., immediate, extended, } \\
\text { spouse) }\end{array}$ \\
\hline $\begin{array}{c}\text { Perceived } \\
\text { behavioural } \\
\text { control }\end{array}$ & $\begin{array}{l}\text { 1. Staff and/or coaches at activities/sports } \\
\text { were not accommodating } \\
\text { 2. Activities/sports were not accessible } \\
\text { 3. Your child did not have extra support } \\
\text { 4. Your child was physically restricted (e.g., } \\
\text { pain, injured, tired) } \\
\text { 5. The variety of activities available were } \\
\text { limited } \\
\text { 6. There was a lack of proper staffing, } \\
\text { support and supervision at organized } \\
\text { sport or physical activities } \\
\text { 7. Your child did not have the proper } \\
\text { equipment to participate } \\
\text { The weather and temperature conditions } \\
\text { were not ideal } \\
\text { 9. Your child had limited time due to school } \\
\text { and other commitments (e.g., medical } \\
\text { appointments and therapy) } \\
\text { 10. The activities were not necessarily safe } \\
\text { for your child }\end{array}$ & $\begin{array}{l}\text { 1. The cost of enrolling your child in } \\
\text { organized sport and physical activity was } \\
\text { high } \\
\text { 2. You have limited time } \\
\text { 3. You experience challenges with } \\
\text { accessibility of the sport/physical activity } \\
\text { 4. You have challenges finding a preferred } \\
\text { physical activity/sport } \\
\text { 5. You have to find extra support for your } \\
\text { child } \\
\text { 6. You have to travel a far distance to } \\
\text { participate } \\
\text { 7. The weather conditions are poor } \\
\text { 8. Your child is in a bad mood } \\
\text { 9. You are concerned about your child's } \\
\text { safety } \\
\text { 10. You are feeling tired, frustrated, or in a } \\
\text { bad mood }\end{array}$ \\
\hline
\end{tabular}

*Attitude for parent PA support was broken into affective and instrumental attitude from the EFA results with associate beliefs listed under each construct

Subjective norm (parent PA support): Participants rated their agreement with five items anchored by "the following people think I should support my child to engage in 60 minutes of physical activity each day" followed by individuals such as: 1) family (e.g., 
immediate, extended, spouse); and 2) disability organizations/programs (Cronbach's $\alpha=$ $0.86 ; \mathrm{KMO}=0.83 ; \chi 2(10)=250.25, \mathrm{P}<.001)$.

Perceived behavioural control (PBC; child PA): Participants rated their agreement with ten items anchored by the statement: "if my child really wanted to and was very motivated to engage in 60 minutes of physical activity each day, he or she could participate even if" followed by statements such as: 1) your child was physically restricted (e.g., pain, injured, tired); and 2) your child did not have the proper equipment to participate (Cronbach's $\left.\alpha=0.79 ; \mathrm{KMO}=0.81 ; \chi^{2}(45)=409.75, \mathrm{P}<.001\right)$.

Perceived behavioural control (PBC; parent PA support): Participants rated their agreement with ten items anchored by the statement: "if you were really motivated and fully committed to support your child to participate in 60 minutes of physical activity each day, how confident are you that you could provide support even if" followed by statements such as: 1) the cost of enrolling your child in organized sport and physical activity was high; and 2) you have to travel a far distance to participate (Cronbach's $\alpha=0.88 ; \mathrm{KMO}=0.88 ; \chi^{2}(45)$ $=561.27, \mathrm{P}<.001$ ).

Intention: Intention to provide parent PA support was measured with two items (Ajzen, 2002). Participants rated agreement with the following statements: 1) I intend to provide support to help my child participate in physical activity 60 minutes each day in the next month; and 2) "In the next month, I will try to provide support to help my child participate in physical activity for 60 minutes per day (Cronbach's $\alpha=0.91 ; \mathrm{KMO}=0.52 ; \chi^{2}$ (1) $=133.08, \mathrm{P}<.001)$.

\section{Multi-process action control framework measures}

The M-PAC measures developed from the current study were used in a recently published study (Tanna et al., 2017) because there were no other known measures for examining parent PA support among parents of CYD at the time of study development. MPAC constructs were assessed on a 5 -point Likert-type scale $(1=$ strongly disagree to $5=$ strongly agree), unless stated otherwise:

Parent PA support habit: Participants rated their agreement with four items (Gardner, Abraham, Lally \& de Bruijn, 2012) anchored by "supporting my child's physical activity is something I" followed by statements such as: 1) do without thinking (Cronbach's $\left.\alpha=0.95 ; \mathrm{KMO}=0.81 ; \chi^{2}(6)=457.71, \mathrm{P}<.001\right)$.

Parent PA support identity: Participants rated their agreement with three statements such as: 1) I consider myself a parent who supports my child's regular physical activity (Cronbach's $\alpha=0.91 ; \mathrm{KMO}=0.73 ; \chi^{2}(3)=197.13, \mathrm{P}<.001$ ). This measure was adapted from the Exercise Identity Scale (Anderson \& Cychosz, 1994) to reflect parent PA support behaviours.

Behavioural regulation of parent PA support: Participants indicated how often they engaged in the following four items on a 5 -point Likert-type scale $(1=$ never to $5=$ always): 1) look for information or opportunities to get active with your child on most days of the week, 2) make a plan to ensure your child engages in PA on most days of the week; 3) keep track of the amount of physical activity your child is getting; and 4) make plans regarding what to do if something interfered with your support of your child's physical activity. This measure was adapted from earlier research examining PA support among parents of children without disabilities (Rhodes et al., 2016). Item 4 was added to capture coping planning (Sniehotta, 2009) and the following item was removed "set goals for how much physical activity my child will get on most days of the week", as there are no specific PA guidelines for CYD (Cronbach's $\alpha=0.75 ; \mathrm{KMO}=0.72 ; \chi^{2}(6)=134.13, \mathrm{P}<.001$ ). 
Parent PA support: Participants indicated how often they engaged in the following five items in the past month on a 5-point Likert-type scale ( $1=$ never/rarely to $5=$ daily): 1 ) encourage my child to participate in physical activity or sport; 2) do a physical activity or play sports with my child; 3) drive or provide transportation so my child could go to a place where he or she can do physical activities or play sports; 4) watch my child participate in physical activity or sport; and 5) tell my child that physical activity is good for his or her health. This measure was adapted from an earlier study examining PA support behaviour (Rhodes et al., 2016) and items four and five were added to the measure to capture additional aspects of parent PA support (Cronbach's $\left.\alpha=0.81 ; \mathrm{KMO}=0.72 ; \mathrm{X}^{2}(10)=188.02, \mathrm{P}<.001\right)$.

\section{Procedure}

Elicitation data were collected from a small sample of parents of CYD $(n=28)$ to inform the development of a scale to measure TPB variables. Following completion of the scale development, recruitment for the main study began and eligible participants provided consent and completed a baseline questionnaire to assess the TPB variables, M-PAC variables, and parent PA support. Participants were then emailed four weeks later to complete a follow-up questionnaire to assess parent PA support. Data were collected using FluidSurveys (www.fluidsurveys.com), an online survey software. All procedures were approved by York University's ethics review committee.

\section{Data Analyses}

Factor analyses to explore scale composition: Average overall composite scores were calculated for each measure after items were reverse-coded, as appropriate. Exploratory factor analysis (EFA) using a principal-component-extraction method and a varimax rotation was conducted for TPB and M-PAC measures to explore the dataset and assess the underlying relationships. Exact Kaiser-Meyer-Olkin (KMO) and Bartlett's Test of Sphericity $\left(\chi^{2}\right)$ values are presented with the measures under the TPB and M-PAC framework constructs headings. Internal consistencies for each scale were also examined and presented with the measures above under the TPB and M-PAC framework constructs headings.

Analysis to predict parent PA support: A hierarchical linear regression analysis was calculated to examine theoretical predictors of parent PA support. TPB variables were entered on step-one and M-PAC variables were entered on step-two.

\section{Results}

\section{Participants}

Parents of CYD $(n=114)$ completed the baseline survey, however 16 participants were lost to follow-up and did not provide a reason for withdrawal. An additional three participants were removed due to incomplete data (i.e., $>20 \%$ missing data), resulting in a total of 95 participants in the final analyses.

\section{Participant Baseline Characteristics}

A description of sample demographic characteristics is available in Table 3 . The participants' CYD ranged in age between $4-30$ years (mean $=12.8 \pm 5.2$ years). The majority of CYD were males (57.9\%) and were affected by developmental (30.5\%) or physical (30.5\%) disabilities.

\section{Data Inspection}

All analyses were conducted using SPSS 19.0. A total of 30 missing values were identified within the dataset and were replaced using the median imputation method for 
each scale item (Chen, Wang \& Chen, 2012). Data were inspected for violations of statistical assumptions (Field, 2009). Scores were adjusted to reduce the impact of univariate outliers (Z-score > 3.29 SD; Tabachnick \& Fidell, 2007). There were eight outlier scores for attitude (child PA), three outlier scores for attitude (parent PA support), one outlier score for subjective norm (child PA) and three outlier scores for subjective norm (parent PA support). These outlier values were removed because the authors were confident that these values were reporting errors by participants and did not reflect the characteristics of the population (Beaumont \& Rivest, 2009). After these outliers were removed, the data were normally distributed.

Table 3. Participant demographic characteristics for elicitation and final samples

\begin{tabular}{|c|c|c|c|c|c|}
\hline \multicolumn{2}{|c|}{ Participant characteristics } & \multicolumn{2}{|c|}{$\begin{array}{l}\text { Elicitation sample } \\
(\mathrm{N}=28)\end{array}$} & \multicolumn{2}{|c|}{$\begin{array}{l}\text { Final sample } \\
\quad(\mathrm{N}=95)\end{array}$} \\
\hline & & $\mathrm{N}$ & $\%$ & $\mathrm{~N}$ & $\%$ \\
\hline \multirow{2}{*}{ Parent Gender } & Male & 2 & 7.1 & 16 & 16.8 \\
\hline & Female & 26 & 92.9 & 79 & 83.2 \\
\hline \multirow{5}{*}{ Parent Age } & $25-34$ & 5 & 17.9 & 6 & 6.3 \\
\hline & $35-44$ & 18 & 64.2 & 36 & 37.9 \\
\hline & $45-54$ & 5 & 17.9 & 45 & 47.4 \\
\hline & $55-64$ & 0 & 0 & 6 & 6.3 \\
\hline & $65+$ & 0 & 0 & 2 & 2.1 \\
\hline \multirow[t]{8}{*}{ Parent Education } & Less than high school/high school & 2 & 7.1 & 3 & 3.2 \\
\hline & Some college (no degree) & 1 & 3.6 & 11 & 11.6 \\
\hline & College degree & 11 & 39.3 & 22 & 23.2 \\
\hline & Some university (no degree) & 1 & 3.6 & 10 & 10.5 \\
\hline & University (Bachelor degree) & 8 & 28.6 & 34 & 35.8 \\
\hline & University (Master's degree) & 4 & 14.3 & 10 & 10.5 \\
\hline & $\begin{array}{l}\text { University (Doctorate } \\
\text { degree/MD) }\end{array}$ & 1 & 3.6 & 1 & 3.2 \\
\hline & $\begin{array}{l}\text { University Professional Post- } \\
\text { Grad Degree }\end{array}$ & 4 & 4.2 & 4 & 4.2 \\
\hline \multirow[t]{6}{*}{ Marital Status } & Single & 2 & 7.1 & 0 & 0 \\
\hline & Common-Law & 4 & 14.3 & 6 & 6.3 \\
\hline & Married & 22 & 78.6 & 83 & 87.4 \\
\hline & Divorced & 0 & 0 & 3 & 3.2 \\
\hline & Other & 0 & 0 & 1 & 3.2 \\
\hline & Do not wish to specify & 0 & 0 & 2 & 6.4 \\
\hline Household & $\$ 35,000$ or less & 3 & 10.7 & 9 & 9.5 \\
\hline \multirow[t]{7}{*}{ Income } & $\leq \$ 35,000-\$ 49,999$ & 3 & 10.7 & 6 & 6.3 \\
\hline & $\$ 50,000-\$ 64,999$ & 4 & 14.3 & 8 & 8.4 \\
\hline & $\$ 65,000-\$ 74,999$ & 1 & 3.6 & 8 & 8.4 \\
\hline & $\$ 75,000-\$ 99,999$ & 6 & 21.4 & 18 & 18.9 \\
\hline & $\$ 100,000-\$ 149,999$ & 6 & 21.4 & 24 & 25.3 \\
\hline & $\$ 150,000+$ & 4 & 14.3 & 10 & 10.5 \\
\hline & Do not wish to report & 1 & 3.6 & 12 & 12.6 \\
\hline \multirow[t]{3}{*}{ Location* } & Ontario & 28 & 100 & 63 & 66.3 \\
\hline & Other Canadian provinces & 0 & 0 & 8 & 14.9 \\
\hline & United States & 0 & 0 & 12 & 12.6 \\
\hline \multirow[t]{2}{*}{ Ethnic Minority } & No & 23 & 82.1 & 78 & 82.1 \\
\hline & Yes & 5 & 17.9 & 17 & 17.9 \\
\hline
\end{tabular}

*13 missing cases from Canada 


\section{Results of Exploratory Factor Analyses}

All scales from the EFA were acceptable and satisfied the statistical assumptions and associated cut-off values for EFA (i.e., determinant value, cut-off $=>0.001$; multicollinearity and singularity; Kaiser-Meyer-Olkin Test for Sampling Adequacy, cut-off $=>0.5$; and Bartlett's Test of Sphericity, cut-off $=\mathrm{p}<0.05$; Field, 2009). There were two different factors for the variable attitude (parent PA support), suggesting the variable be broken into the two commonly observed components: affective and instrumental attitudes (Ajzen, 1991). French and colleagues (2005) suggest that TPB measures should consider both affective and instrumental determinants of attitudinal behaviour and these measures have been commonly seen among other TPB measures of parent PA support (Rhodes et al., 2013; Rhodes et al., 2016). Affective attitude refers to a person's affective experience of performing a behaviour (e.g., frustration), whereas instrumental attitude refers to the cognitive considerations of whether performing a behaviour would be advantageous (e.g., bond with child; Rhodes, 2017). Within M-PAC, both instrumental and affective attitude are considered reflective motivational constructs and important antecedents of intention and behaviour (Rhodes, 2017).

\section{Results of Regression to Identify Theoretical Predictors of Parent PA Support}

A hierarchical linear regression was conducted to identify theoretical predictors of parent PA support (Table 4). TPB variables were entered into the model on step one, and MPAC variables were added on step two. The two-step approach was used to allow for an understanding of pre- (i.e., TPB) and post-intentional (i.e., M-PAC) variables as predictors of parent PA support.

Table 4. Hierarchical regression results of theoretical predictors of parent PA support

\begin{tabular}{|c|c|c|c|c|c|}
\hline & $\mathbf{R 2}$ & $\mathbf{R 2} \Delta$ & $\mathbf{p}$ & Std B & $95 \% \mathrm{CI}$ \\
\hline \multicolumn{6}{|l|}{ Step 1} \\
\hline Constant & 0.51 & 0.51 & 0.68 & & $-0.88-1.34$ \\
\hline Attitude (child PA) & & & 0.21 & -0.15 & $-0.53-0.12$ \\
\hline Attitude (parent PA support - instrumental) & & & 0.049 & 0.24 & $-0.002-0.59$ \\
\hline Attitude (parent PA support - affective) & & & 0.39 & 0.08 & $-0.09-0.25$ \\
\hline Subjective norm (child PA) & & & 0.67 & 0.06 & $-0.22-0.35$ \\
\hline Subjective norm (parent PA support) & & & 0.88 & 0.02 & $-0.23-0.27$ \\
\hline PBC (child PA) & & & 0.04 & 0.19 & $0.01-0.37$ \\
\hline PBC (parent PA support) & & & 0.049 & 0.19 & $-0.002-0.32$ \\
\hline Intention & & & $<0.001$ & 0.42 & $0.17-0.51$ \\
\hline \multicolumn{6}{|l|}{ Step 2} \\
\hline Constant & 0.70 & 0.18 & 0.74 & & $-1.09-0.78$ \\
\hline Attitude (child PA) & & & 0.16 & -0.14 & $-0.46-0.08$ \\
\hline Attitude (parent PA support - instrumental) & & & 0.26 & 0.12 & $-0.11-0.39$ \\
\hline Attitude (parent support - affective) & & & 0.51 & 0.05 & $-0.09-0.19$ \\
\hline Subjective norm (child PA) & & & 0.73 & 0.04 & $-0.19-0.28$ \\
\hline Subjective norm (parent PA support) & & & 0.86 & -0.02 & $-0.23-0.19$ \\
\hline PBC (child PA) & & & 0.03 & 0.17 & $0.02-0.32$ \\
\hline PBC (parent PA support) & & & 0.37 & 0.07 & $-0.07-0.19$ \\
\hline Intention & & & 0.003 & 0.27 & $0.08-0.36$ \\
\hline Behavioural regulation of parent PA support & & & 0.32 & 0.36 & $0.03-0.1$ \\
\hline Parent PA support habit & & & 0.34 & 0.15 & $0.01-0.2$ \\
\hline Parent PA support identity & & & $<0.001$ & 0.21 & $0.02-0.43$ \\
\hline
\end{tabular}

Note. PBC = perceived behavioural control, Dependent variable is parent PA support $R^{2}=0.51$ for Step 1, $\Delta R^{2}=$ 0.18 for Step $2(p<0.001)$ Std B = Standardised beta, CI = Confidence Interval 
The first model was statistically significant with TPB variables explaining approximately $51 \%$ of the variance in parent PA support $(\mathrm{F}(8,80)=10.57, \mathrm{p}<0.001)$. Statistically significant predictors of parent PA support $(\mathrm{p}<.05)$ included instrumental attitude (parent PA support; $\beta=0.24 ; 95 \%$ CI [-0.002, 0.59]), PBC (child PA; $\beta=0.19 ; 95 \%$ CI [0.01, 0.37]), PBC (parent PA support; $\beta=0.19 ; 95 \%$ CI [-0.002, 0.32]), and intentions ( $\beta=0.42 ; 95 \% \mathrm{CI}$ $[0.17,0.51])$. On step 2, the M-PAC variables explained an additional $18 \%$ of the variance in parent PA support $(\mathrm{F}(11,77)=15.94, \mathrm{p}<0.001)$ such that the final model explained $70 \%$ of the variance in parent PA support. Statistically significant predictors of parent PA support ( $\mathrm{p}<.05$ ) in the final model included: PBC (child PA; $\beta=0.17 ; 95 \%$ CI [0.02, 0.32]), intentions ( $\beta=0.27$; 95\% CI [0.08, 0.36]), behavioural regulation of parent PA support ( $\beta$ $=0.36 ; 95 \% \mathrm{CI}[0.03,0.1])$, parent PA support habit $(\beta=0.15 ; 95 \% \mathrm{CI}[0.01,0.2])$, and parent PA support identity ( $\beta=0.21 ; 95 \%$ CI [0.02, 0.43]). Cohen's f2 was calculated to measure effect sizes with both models (Selya et al., 2012), step $1(\mathrm{f} 2=1.06)$ and step 2 ( $f_{2}=$ 2.28), which represented large effect sizes (i.e., f2 $\geq 0.35$; Cohen, 1988).

\section{Discussion}

Guided by the TPB and M-PAC frameworks, the purpose of this study was to examine pre- and post-intentional predictors of PA support among parents of CYD. In order to address criticisms of the TPB regarding the intention-behaviour gap (Conner \& Norman, 2005) and address limitations highlighted in previous research regarding the potential importance of post-intentional factors in facilitating PA support among parents of CYD (Tanna et al., 2017), both pre-intention (i.e., TPB) and post-intention variables (i.e., M-PAC) were examined as predictors of parent PA support. The first model (i.e., TPB variables) found intention and PBC were predictors of parent PA support along with instrumental attitude for parent PA support. These findings are consistent with other parent PA support research, which has emphasized the importance of intention, PBC, and attitudes in understanding parent PA support (Rhodes et al., 2013; Rhodes et al., 2016).

Subjective norm has typically been found to play a modest role in predicting intention, with no relationship to behaviour within the TPB (Bandura, 1994), and therefore an adapted TPB model (without subjective norms) has been commonly applied. Consistent with previous parent PA support research (Rhodes et al., 2013; Rhodes et al., 2016), the current study found that subjective norms was not a predictor of parent PA support. Although recent research has suggested that subjective norm is unnecessary to measure (e.g., M-PAC framework does not include subjective norms; Rhodes, 2017), the current study measured subjective norms as the research regarding parental PA support for CYD is limited. Although the findings regarding subjective norms were null, caution should be used before discrediting this construct in behaviour adoption for this population and should instead continue to measure normative beliefs among a larger sample of parents of CYD. Overall, the TPB variables explained $51.4 \%$ of the variance in parent PA support with intention serving as the strongest predictor of behaviour.

When post-intentional (i.e., M-PAC) variables were added, the model explained an additional $18 \%$ of the variance of parent PA support. Among TPB variables, intention and PBC remained as significant predictors of parent PA support. Among M-PAC variables, behavioural regulation, habit and identity were significant predictors of parent PA support. This final model provides support for the value in considering post-intentional factors to understand PA support behaviour among parents of CYD. Specifically, the model supports the M-PAC structure in highlighting post-intentional concepts to advance our understanding beyond that of models such as the TPB, which consider intentions to be the most proximal predictor of behaviour. Interventions to enhance PA support among parents 
of CYD should most certainly target post-intentional factors, particularly among parents who already have strong intentions which is likely the case for the majority of parents (Jeong et al., 2015).

Behavioural regulation was the strongest predictor of parent PA support and involves strategies such as action and coping planning, and self-monitoring (Rhodes, 2017). Behavioural regulation strategies are critical until one develops more reflexive strategies (e.g., habit) to maintain behaviour (Rhodes, 2017). Behavioural regulation strategies have been shown to increase PBC for parent PA support (Brown et al., 2016) and are an important correlate of PA support among parents of CYD (Tanna et al., 2017). Parents of CYD desire information and tools to support their behavioural regulation of PA support (Bassett-Gunter et al., 2017). Evidence-based strategies to enhance parents' behavioural regulation may be of great value in both supporting PA support directly, as well as indirectly through enhanced PBC. Indeed, strategies that target behavioural regulation might be important to facilitate successful experiences in providing parent PA support, which in turn could support PBC and continued support until ultimately habit and identity factors facilitate sustained PA support. There is great value in research to develop and evaluate interventions to support behavioural regulation for PA support among parents of CYD.

Habit was also identified as a predictor of parent PA support. Habit is a process of behavioural patterns learned through repetition, which reinforces context-specific behaviour associations (Gardner, de Bruijn \& Lally, 2011). The process involves cueing a habitual response automatically when subsequent behaviours are encountered, allowing for sustained behaviour that requires low intentionality or effort (Gardner et al., 2011). Although the antecedents of habit are not clear, past performance and repetition under similar contexts may allow for habit development (Lally \& Gardner, 2013). Behavioural regulation strategies may be valuable in supporting the development of habit. For example, in the context of parent PA support, it seems as though successful repetition under similar cues (e.g., family PA after dinner) may lead to habit development which can be facilitated through increased behavioural regulation (Fleig et al., 2013). However, it should be noted that habit development for this population (i.e., parents of CYD) may need to be approached differently given the uniqueness of this sample and their specific needs. General parental support (i.e., not specific to PA) is crucial in the overall well-being of CYD (Antle et al., 2007) and certain behaviours might require conscious attention. Therefore, habit development for certain PA behaviours might be counterproductive for parents of CYD, given the need for flexibility. However, certain parent PA support behaviours, such as action and coping planning and self-monitoring, may be feasible for habit development, which have been shown to be effective behavioural regulation strategies among this population (Tanna et al., 2017). Future research should further explore the role of habit among parents of CYD, particularly which behaviours are feasible for habit development.

Identity was also identified as a predictor of parent PA support. Identity is a reflexive construct representing how individuals perceive themselves in a specific role (Burke, 2006). Identity has been recognized as an important motivational component (Kearney \& O'Sullivan, 2003). It is thought that identity is automatically activated when an individual is faced with a situation that is either aligned or mismatched to their behaviour (Rhodes et al., 2016). A fundamental antecedent of identity is behavioural experience and therefore identify is strengthened overtime (Stryker \& Burke, 2000). Further research is necessary to understand the relationship between behavioural regulation, habit and identity, as well identify the optimal strategies to foster these constructs and ultimately parent PA support behaviour. 
Evidence-based interventions should be designed to boost motivation while subsequently facilitating the translation of intentions into behaviour through behavioural regulation and strategies that foster habit and identity. Perhaps "matched" intervention approaches would be superior to a one size fits all approach (Bloemen et al., 2017). For example, a parent with low motivation and poor attitudes toward parent PA support might benefit from an educational intervention regarding: (i) the benefits of child PA and parent PA support and (ii) perceptions of PBC. Alternatively, a parent with high intentions toward PA support might benefit from a skills-based intervention to develop behavioural regulation skills and enhance habit and identity. Further research to inform the design and implementation of strategies that meet the unique needs of various parents of CYD is needed (Bloemen et al., 2017). For certain, effective strategies that target post-intentional constructs are needed to enact behaviour (Rhodes, 2017).

\section{Limitations, Strengths, and Future Research Directions}

The current study had limitations that warrant discussion. The study had a relatively small sample size, which may have affected the results and limited power to detect significant predictors of parent PA support. Although the sample did include some fathers and some parents who self-identified as an ethnic minority, the participants were primarily highly educated, married, Caucasian mothers, which limits the generalizability of these findings. Finally, data regarding parent PA support were collected through self-report, which may not be accurate and subject to response bias. For example, the strong relationship between reflexive M-PAC constructs (i.e., habit and identity) and parent PA support suggests that parents in the sample likely had some experience with parent PA support. The study also had important strengths; for example, scale development and analysis processes were employed to a) develop a population-specific tool to measure TPB variables, and b) explore psychometric properties of all scales used in the study. The outcomes of the factor analyses (i.e., EFA) and good scale reliability demonstrated in the current study, give further confidence in the applicability of the tools for use in future research. It is recommended that future research consider additional psychometric analyses on these measures (e.g., confirmatory factor analyses).

\section{Conclusions}

This study supports the notion that theoretical frameworks which include postintentional factors show promise to further the understanding of parent PA support behaviour (Rhodes et al., 2016). Researchers and interventionist should consider postintentional constructs as important factors in understanding parent PA support among parents of CYD.

Future research should focus on further understanding post-intentional factors of parent PA support, particularly considering strategies that support behavioural regulation skills, and subsequent habit and identity formation, which may be of particular value in fostering parent PA support, and ultimately enhanced PA among CYD.

\section{Perspectives}

The current study extends the work by Jeong et al. (2015), who examined parent support for PA among CYD and investigated whether parental beliefs and intentions predicted parent support for PA using the TPB. Although understanding predictors of intention are important, numerous studies have found that parents (Rhodes et al., 2013), including parents of CYD (Tanna et al., 2017), have positive intentions to support their child's PA participation, however they have difficulty translating those intentions into behaviour (Rhodes et al., 2016; Jeong et al., 2015). Therefore, future research must look beyond the 
TPB and beyond intentions, to further understand predictors of behaviour. The results from the current study suggest the importance of both pre- and post-intentional predictors but highlight the significance of post-intentional factors to understand parent PA support behaviour. Furthermore, the results of the study can inform the design and implementation of interventions and PA programs to support parents of CYD who already face many barriers and challenges in supporting PA for CYD.

Author affiliations:

1310 Stong College School of Kinesiology and Health Science, York University, Toronto, Ontario M3P 1J3 Canada; rgunter@yorku.ca, sunitat@yorku.ca

2 Faculty of Kinesiology and Physical Education, Room BN 327, 55 Harbord Street, University of Toronto, Toronto, Ontario M5S 2W6 Canada; kelly.arbour@utoronto.ca

3 A366 MacLaurin Building, School of Exercise Science, Physical and Health Education, University of Victoria, Victoria, British Columbia V8W 3N4 Canada; rhodes@uvic.ca

4 The Steadward Centre, 1-670 Van Vliet Complex, University of Alberta, Edmonton, Alberta, T6G1P7; jennifer.leo@ualberta.ca

* Correspondence: rgunter@yorku.ca ; Tel.: +1 416-736-2100 ext. 22072

Author Contributions: Conceptualization, R.B.G., K.A.N., R.R., and J.L; Methodology, R.B.G, S.T., R.R., and K.A.N.; Formal Analysis, S.T., and R.B.G.; Writing-Original Draft Preparation, R.B.G., and S.T.; Writing-Review \& Editing, R.B.G, S.T., R.R., K.A.N., and J.L.

Funding: This research was funded by The Social Sciences and Humanities Research Council of Canada grant number 430-2015-00564.

Acknowledgments: The authors would like to acknowledge the contributions of Aria Kamarhie and Yasaman Soltani.

Conflicts of Interest: The authors declare no conflict of interest.

\section{References}

Ajzen, I. (1991). The theory of planned behavior. Organizational Behavior and Human Decision Processes, 50(2), 179-211. https://doi.org/10.1016/0749-5978(91)90020-T

Ajzen, I. (2002). Constructing a TpB Questionnaire: Conceptual and Methodological Considerations.

https://pdfs.semanticscholar.org/0574/b20bd58130dd5a961f1a2db10fd1fcbae95d.pdf

An, J., \& Goodwin, D. L. (2007). Physical education for students with spina bifida: Mothers' perspectives. Adapted Physical Activity Quarterly, 24(1), 38-58. https://doi.org/10.1123/apaq.24.1.38

Anderson, D. F., \& Cychosz, C. M. (1994). Development of an exercise identity scale. Perceptual and Motor Skills, 78(3), 747-751. https://doi.org/10.2466/pms.1994.78.3.747

Antle, B. J., Mills, W., Steele, C., Kalnins, I., \& Rossen, B. (2007). An exploratory study of parents' approaches to health promotion in families of adolescents with physical disabilities. Child: Care, Health and Development, 34(2), 185-193. https://doi.org/10.1111/j.1365-2214.2007.00782.x

Bandura, A. (1994). Self-efficacy. In V. S. Ramachaudran \& H. Friedman (Eds.), Encyclopedia of human behavior (Vol. 4, pp. 71-81). Academic Press.

Bassett-Gunter, R. L., Ruscitti, R. J., Latimer-Cheung, A. E., \& Fraser-Thomas, J. L. (2017). Targeted physical activity messages for parents of children with disabilities: A qualitative investigation of parents' informational needs and preferences. Research in Developmental Disabilities, 64, 37-46. http://doi.org/10.1016/j.ridd.2017.02.016

Beaumont, J. F., \& Rivest, L. P. (2009). Dealing with outliers in survey data. In C. R. Rao (Ed.), Handbook of Statistics (Vol. 29, pp. 247-279). Elsevier.

Beets, M. W., Cardinal, B. J., \& Alderman, B. L. (2010). Parental social support and the physical activity-related behaviors of youth: A review. Health Education \& Behavior, 37(5), 621-644. https://doi.org/10.1177/1090198110363884

Bloemen, M., Van Wely, L., Mollema, J., Dallmeijer, A., \& de Groot, J. (2017). Evidence for increasing physical activity in children with physical disabilities: a systematic review. Developmental Medicine \& Child Neurology, 59(10), 1004-1010. 
Brown, H. E., Atkin, A. J., Panter, J., Wong, G., Chinapaw, M., \& Van Sluijs, E. M. (2016). Family-based interventions to increase physical activity in children: a systematic review, meta-analysis and realist synthesis. Obesity Reviews, 17(4), 345-360. https://doi/org/10.1111/obr.12362

Burke, P. J. (2006). Identity change. Social Psychology Quarterly, 69(1), 81-96. https://doi.org/10.1177/019027250606900106

Chen, S. F., Wang, S., \& Chen, C. Y. (2012). A simulation study using EFA and CFA programs based the impact of missing data on test dimensionality. Expert Systems with Applications, 39(4), 4026-4031. https://doi.org/10.1016/j.eswa.2011.09.085

Cohen, J. (1988). Statistical power analysis for the behavioral sciences (2nd ed.). L. Erlbaum Associates

Cohen, J. (2013). Statistical power analysis for the behavioral sciences. Academic press.

Conner, M., \& Norman, P. (2005). Predicting health behavior (2nd ed.). Open University Press.

Field, A. (2009). Discovering statistics using SPSS: Introducing statistical method (3rd ed.). Sage Publications.

Fleig, L., Pomp, S., Parschau, L., Barz, M., Lange, D., Schwarzer, R., \& Lippke, S. (2013). From intentions via planning and behavior to physical exercise habits. Psychology of Sport and Exercise, 14(5), 632-639. https://doi.org/10.1016/j.psychsport.2013.03.006

Francis, J., Eccles, M. P., Johnston, M., Walker, A. E., Grimshaw, J. M., Foy, R., Kanner, E. F. S., Smith, L. \& Bonetti, D. (2004). Constructing questionnaires based on the theory of planned behavior: A manual for health services researchers. Centre for Health Services Research; University of Newcastle.

French, D. P., Sutton, S., Hennings, S. J., Mitchell, J., Wareham, N. J., Griffin, S., Hardeman, W., Kinmonth, A. L. (2005). The importance of affective beliefs and attitudes in the theory of planned behavior: Predicting intention to increase physical activity. Journal of Applied Social Psychology, 35(9), 1824-1848. https://doi.org./ 10.1111/j.1559-1816.2005.tbo2197.x

Gardner, B., Abraham, C., Lally, P., \& de Bruijn, G. J. (2012). Towards parsimony in habit measurement: Testing the convergent and predictive validity of an automaticity subscale of the Self-Report Habit Index. International Journal of Behavioral Nutrition and Physical Activity, 9(1), 102. https://doi.org/10.1186/1479-5868-9-102

Gardner, B., de Bruijn, G. J., \& Lally, P. (2011). A systematic review and meta-analysis of applications of the self-report habit index to nutrition and physical activity behaviors. Annals of Behavioral Medicine, 42(2), 174-187. https://doi.org10.1007/s12160-0119282

Hancock, J. A. (2013). Exploration of five condom-related behaviors in the UK: Development and evaluation of theory-based online safer sex intervention. [Unpublished doctoral dissertation]. Coventry University.

Jeong, M., Kim, S. Y., \& Lee, E. (2015). Parents' beliefs and intentions toward supporting physical activity participation for their children with disabilities. Adapted Physical Activity Quarterly, 32(2), 93-105. https://doi.org/10.1123/APAQ.2013-0106

Kearney, M. H., \& O'Sullivan, J. (2003). Identity shifts as turning points in health behavior change. Western Journal of Nursing Research, 25(2), 134-152. https://doi.org/10.1177/019394590225003

Kowalchuk, K., \& Crompton, S. (2009). Living with disability series: Social participation of children with disabilities. Canadian Social Trends, 88, 63-72.

Lally, P., \& Gardner, B. (2013). Promoting habit formation. Health Psychology Review, 7(sup1), S137-S158. https://doi.org/10.1080/17437199.2011.603640

Perry, A., \& Weiss, J. (2014). Canadian children with severe developmental disabilities: A survey of health, well-being and social inclusion. York University. http://www.go4kidds.ca/documents/FINALGO4KIDDSREPORTCARD.pdf

Rhodes, R. E. (2017). The evolving understanding of physical activity behavior: A multiprocess action control approach. Advances in Motivation Science, 4, 171-205. https://doi.org/10.1016/bs.adms.2016.11.001 
Rhodes, R. E., Berry, T., Craig, C. L., Faulkner, G., Latimer-Cheung, A., ... Tremblay, M. S. (2013). Understanding Parental Support of Child Physical Activity Behavior. American Journal of Health Behavior, 37(4), 469-477. https://doi.org/10.5993/AJHB.37.4.5

Rhodes, R. E., \& de Bruijn, G. J. (2013). How big is the physical activity intention-behavior gap? A meta-analysis using the action control framework. British Journal of Health Psychology, 18(2), 296-309. https://doi.org/10.1111/bjhp.12032

Rhodes, R. E., Naylor, P. J., \& McKay, H. A. (2010). Pilot study of a family physical activity planning intervention among parents and their children. Journal of Behavioral Medicine, 33(2), 91-100. https://doi.org/10.1007/s10865-009-9237-0

Rhodes, R. E., Plotnikoff, R. C., \& Spence, J. C. (2004). Creating parsimony at the expense of precision? Conceptual and applied issues of aggregating belief-based constructs in physical activity research. Health Education Research, 19(4), 392-405. https://doi.org/10.1093/her/cyg043

Rhodes, R. E., Spence, J. C., Berry, T., Deshpande, S., Faulkner, G., Latimer-Cheung, A. E., O'Reilly, N., \& Tremblay, M. S. (2016). Understanding action control of parental support behavior for child physical activity. Health Psychology, 35(2), 131. https://doi.org/10.1037/hea000023

Selya, A. S., Rose, J. S., Dierker, L. C., Hedeker, D., \& Mermelstein, R. J. (2012). A practical guide to calculating Cohen's f2, a measure of local effect size, from PROC MIXED. Frontiers in Psychology, 3, 111. https://doi.org/10.3389/fpsyg.2012.00111

Sniehotta, F. F. (2009). Towards a theory of intentional behavior change: Plans, planning, and self-regulation. British Journal of Health Psychology, 14(2), 261-273. https://doi.org/10.1348/135910708X389042

Stewart, D. A., Law, M. C., Rosenbaum, P., \& Willms, D. G. (2002). A qualitative study of the transition to adulthood for youth with physical disabilities. Physical \& Occupational Therapy in Pediatrics, 21(4), 3-21. https://doi.org/10.1080/Joo6v21no4 02

Stryker, S., \& Burke, P. J. (2000). The past, present, and future of an identity theory. Social Psychology Quarterly, 62(4), 284-297. https://doi.org/10.2307/2695840

Tabachnick, B. G., \& Fidell, L. S. (2007). Using multivariate statistics ( $7^{\text {th }}$ ed.). Pearson Education.

Tanna, S., Arbour-Nicitopoulos, K., Rhodes, R. E., \& Bassett-Gunter, R. (2017). A pilot study exploring the use of a telephone-assisted planning intervention to promote parental support for physical activity among children and youth with disabilities. Psychology of Sport and Exercise, 32, 25-33. https://doi.org/10.1016/i.psychsport.2017.05.003

United Nations (2012). Youth with Disabilities. United Nations Department of Economic and Social Affairs. https://www.un.org/esa/socdev/documents/youth/factsheets/youth-with-disabilities.pdf

Yao, C. A., \& Rhodes, R. E. (2015). Parental correlates in child and adolescent physical activity: a meta- analysis. International Journal of Behavioral Nutrition and Physical Activity, 12(1), 10. https://doi.org/10.1186/s12966-015-0163-y

Yao, W., Shapiro, D.R., \& Liao, C. (2016). Parents motivation for participation in physical activity for children with impairments. European Journal of Adapted Physical Activity, 9(1), 15-26. https://doi.org/10.5507/euj.2016.002

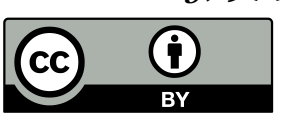

(C) 2020 by the authors. Submitted for possible open access publication under the terms and conditions of the Creative Commons Attribution (CC BY) license (http://creativecommons.org/licenses/by/4.o/). 